\title{
PROBLEMÁTICA EN TORNO A LA LIMITACIÓN DE LA PRESTACIÓN EN LOS SEGUROS DE RESPONSABILIDAD CIVIL EN PARAGUAY ${ }^{*}$
}

\section{PROBLEMATIC AROUND THE LIMITATION OF THE PROVISION IN LIABILITY INSURANCE IN PARAGUAY}

\author{
SANDRA MARÍA ANTOLA-ORTIZ** \\ ZUNILDA MARÍA ASUNCIÓN BENAVENTE FERREIRA ${ }^{* * *}$
}

Fecha de recepción: 1 de julio de 2017 Fecha de aceptación: 15 de agosto de 2017 Disponible en línea: 30 de noviembre de 2017

\section{Para Citar este articulo/To cite this article}

\begin{abstract}
Antola Ortiz, Sandra María \& Benavente Ferreira, Zunilda María Asunción, Problemática en torno a la limitación de la prestación en los seguros de responsabilidad civil en Paraguay, 47 Rev.Ibero-Latinoam. Seguros, 77-106 (2017). https://doi.org/10.11144/Javeriana.ris47.ptlp

doi:10.11144/Javeriana.ris47.ptlp
\end{abstract}

* Artículo de reflexión, desarrollado a partir de la conferencia dictada por las autoras en el marco ponencia relatoría de la sección paraguaya de AIDA, en el XIV Congreso del Comité Iboerolatinoamericano de AIDA - CILA. Santa Cruz de la Sierra - Bolivia. 2 a 5 de mayo de 2017.

** Abogada de la Facultad de Ciencias Jurídicas y Diplomáticas de la Universidad Católica de la ciudad de Asunción. Desde su egreso incursiono en el mundo del derecho de seguros, siendo abogada de compañías de seguros, grupo coasegurador. - durante su trayectoria profesional dio charlas en la Universidad Católica, fue expositora en los congresos de CILA 2015 Cuba, CILA 2017 Bolivia, seminarios internacionales y nacionales. - Contacto: santola@consolidada.com.py

*** Abogada por la Facultad de Ciencias Jurídicas y Diplomáticas de la Universidad Católica Ntra. Señora de la Asunción. Miembro de la Comisión Directiva de AIDA - SECCIÓN PARAGUAYA - Cargo: Tesorera Socia Fundadora y Actual Vicepresidente del Instituto de Derecho de Seguros del Paraguay. Miembro titular del Comité Jurídico de la Asociación Paraguaya de Compañías de Seguros Integrante en calidad de Secretaria del Grupo de Trabajo CILA - Seguro de Vida, Pensiones y Seguros Colectivos. Coordinador Nacional en representación de AIDA -SECCIÓN PARAGUAYA, encargada de la comunicación y vínculo con el directorio de ARIAS-LATAM. Contacto: z_benavente@hotmail.com 


\section{RESUMEN}

El mercado asegurador paraguayo no cuenta con una regulación legal o administrativa que obligue a tomar ciertos y determinados valores máximos o mínimos para el otorgamiento de la cobertura de responsabilidad civil.

Se caracteriza porque el mismo es voluntario. El único seguro obligatorio por ley, es el Seguro de accidentes a pasajeros.

Palabras clave: Seguro de responsabilidad civil voluntario; Obligación de indemnizar dentro de los limites pactados 


\begin{abstract}
The Paraguayan insurance market does not count with a legal or administrative regulation that forces to take certain and determined maximum or minimum values for the conferment of liability coverage.

It is characterized for being voluntary. The only obligatory insurance by law, is the accident insurance for passengers.
\end{abstract}

Keywords: Voluntary liability insurance; Obligation to indemnify within the agreed limits.

\title{
SUMARIO
}

INTRODUCCIÓN: RESPONSABILIDAD CIVIL EN EL CONTRATO DE SEGUROS. 1. ELEMENTOS ESENCIALES DE LA RESPONSABILIDAD CIVIL; 1.1. La conducta. 1.2. La antijuridicidad. 1.3. El daño. 1.4. Nexo causal. 1.5. Factor legal de atribución de imputabilidad al actor. Conclusión. 2. EXIMENTES DE RESPONSABILIDAD CIVIL O QUE ROMPEN EL VÍNCULO CAUSAL: 2.1. Fuerza mayor o caso fortuito. 2.2. Hecho de un tercero. 2.3. Culpa exclusiva de la víctima. Conclusión. 3. ELEMENTOS ESENCIALES DEL SEGURO CONTRA LA RESPONSABILIDAD CIVIL: 3.1. Consentimiento. 3.2. Riesgo asegurado. 3.3. Interés asegurable. 3.4. El daño. 4. EL SEGURO DE LA RESPONSABILIDAD CIVIL EN PARAGUAY. 5. LA PROBLEMÁTICA DEL SEGURO DE RESPONSABILIDAD CIVIL EN PARAGUAY. 6. ELEMENTOS EXÓGENOS QUE INCIDEN EN LA PROBLEMÁTICA DE LOS SEGUROS DE RESPONSABILIDAD CIVIL. 7. EL SEGURO DE RESPONSABILIDAD CIVIL EN LA LEGISLACIÓN PARAGUAYA. 8. SUMAS ASEGURABLES EN RESPONSABILIDAD CIVIL EN NUESTRO SISTEMA CONTRACTUAL. 9. CRITERIOS JURISPRUDENCIALES EN PARAGUAY. Conclusiones. 10. ESTADÍSTICAS DE ALGUNOS PAÍSES DE LATINOAMÉRICA CON RELACIÓN A LAS COBERTURAS DE RESPONSABILIDAD CIVIL Y EL SEGURO OBLIGATORIO. CONCLUSIÓN. BIBLIOGRAFÍA 


\section{INTRODUCCIÓN}

\section{La responsabilidad civil en el contrato de seguros}

Para empezar a hablar de la figura jurídica de la Responsabilidad Civil en el contrato de seguros, debemos circunscribirnos en analizar:

¿Cuando existe responsabilidad civil? Y decimos que existe responsabilidad civil cuando una persona ocasiona daño a otra de la cual deriva su responsabilidad.

¿Porque existe la responsabilidad civil? Porque se causa un daño o un perjuicio.

Lo fundamental del contrato de seguros, es que podemos decir que la responsabilidad civil extracontractual es asegurable, esto ocurre cuando las aseguradoras se obligan mediante un contrato de seguros a reparar el daño causado por su asegurado. Esta circunstancia se da porque la responsabilidad civil tiene una finalidad puramente indemnizatoria o compensatoria y no sancionadora o punitiva.

Existen así dos responsables frente al perjuicio causado:

El sujeto que causo el daño, o asegurado.

El sujeto que se obligó contrato mediante a reparar el daño, o asegurador.

La responsabilidad del primero, "asegurado", deriva del hecho dañoso.

La responsabilidad del segundo "asegurador", deriva del contrato.

$\mathrm{Y}$ es en cuanto a la responsabilidad que asume el asegurador, que entramos a analizar si puede tener limitaciones en cuanto al monto y en cuanto a las clausulas, y esto va desarrollándose conforme la concepción, fundamento y función que cumple el seguro de responsabilidad civil, que se trasunta en corrientes y teorías y que hoy día dan motivo disimiles y controvertidas jurisprudencias que nos llevan en este congreso a desmenuzar la función que cumple el seguro de responsabilidad civil y la problemática en torno a la limitación de la prestación que otorga el contrato. 
No podemos soslayar que el Seguro "per se", cumple en la vida de las sociedades organizadas una función tuitiva de sus integrantes y por ende, social, el fin del seguro es la solidaridad entre los hombres, la humanización del contrato de seguros se impone como valor indiscutible de su objetivo moral, pero ello necesariamente requiere de un equilibrio para que en esa ecuación de intereses resulte en beneficio de todos, pues no se podría, so pretexto de proteger al más débil desproteger a otros.

E ahí, que nos avocamos a analizar por qué son importantes los límites en las prestaciones de los seguros de responsabilidad civil?, tiene un fundamento lógico, jurídico, racional que sustente que dichas prestaciones sean limitadas? Las posiciones y vertientes son tantas, como intereses haya; lo fundamental es que entendemos debe haber en la interpretación y aplicación, que las legislaciones, los órganos de control y reglamentación, y los órganos jurisdiccionales, mantengan una unidad de criterio pacifica, flexible y sin arbitrariedades en pos del bienestar de las partes involucradas, (asegurado, asegurador, y tercero).

Entendemos que la problemática de limitar coberturas en el seguro de responsabilidad civil ya surge de las mismas doctrinas de esta institución jurídica, como así también de principios técnicos no menos importantes que los morales y que le deben dar un marco razonable en pos del objetivo, cual es el de reparar el daño.

Si existen posturas radicales, sentencias de favor, criterios parcialitas y populistas, esto hace sucumbir a las instituciones, incluso aquellas más nobles en su esencia, como es en este caso, el seguro de la responsabilidad civil.

\section{ELEMENTOS ESENCIALES DE LA RESPONSABILIDAD CIVIL}

Del análisis doctrinal, podemos decir que los elementos esenciales son:

1.1. La conducta: El hecho humano o conducta es el primer presupuesto de la responsabilidad civil. El hecho, acción, u obrar humano está relacionado con la noción de acontecimiento. El hecho humano para ser tal requiere ser atribuido a un agente: autoría. Ello ocurre cuando el acto u omisión proviene de una mera causación psíquica. 
1.2. La antijuridicidad: Como presupuesto de la responsabilidad civil implica contradicción de la acción con el ordenamiento jurídico. La acción o el hecho genera responsabilidad civil cuando es antijurídica, es decir cuando es contrario a derecho, lo que provoca la obligación de resarcir.

Puede provenir tanto de la oposición a la ley, como al orden público, moral y buenas costumbres, principios generales del derecho, o toda otra norma cultural reconocida jurídicamente.

1.3. El daño: Constituye otro de los presupuestos necesarios para la existencia de responsabilidad civil.

Decimos que el daño, es la lesión o menoscaba a un interés patrimonial o extra patrimonial, acaecido como consecuencia de una acción.

Tiene que haber daño para que haya responsabilidad porque la acción antijurídica aun imputable al autor, no es punible si no ocasiona un daño. El daño, debe ser cierto, no eventual o hipotético, y acreditado, debe ser susceptible de apreciación pecuniaria.

1.4. Nexo causal: Vínculo que se une a una causa con su efecto, en términos del derecho de la responsabilidad, es la relación causal entre la conducta del agente y el daño sufrido por la victima.

Necesariamente tiene que haber un nexo entre el hecho imputable y el daño, que demuestre la relación causa - efecto.

1.5. Factor legal de la atribución de imputabilidad al actor: Ruben Stiglitz, en su obra Derecho de Seguros, señala que el factor legal de atribución es otro presupuesto de la responsabilidad civil. Supone la preexistencia de imputabilidad del agente y voluntariedad en su obrar. La imputabilidad implica la aptitud de la persona para cometer hechos ilícitos, con total independencia de que en rigor los haya cometido. La imputabilidad, junto con la voluntariedad, constituye presupuesto de la culpabilidad. De manera que, "constatada la falta de discernimiento no puede ni hablarse de culpabilidad, porque ésta carecería de base. Para ser culpable hay que empezar por poder serlo", que la persona pueda razonar, que sepa lo que hace. 


\section{Conclusión}

Para que exista responsabilidad civil debe verificarse la existencia de un hecho o conducta (acción, omisión o creación de riesgo) que cause un perjuicio, y un título de imputación que permita atribuirle al agente las consecuencia negativas de ese daño.

\section{EXIMENTES DE RESPONSABILIDAD CIVIL O QUE ROMPEN EL VÍNCULO CAUSAL}

2.1. Fuerza mayor o caso fortuito: Corresponde a un hecho imprevisible e irresistible que da origen al perjuicio. Los daños producidos por un terremoto, por ej. Escapan del juicio de responsabilidad por derivarse de una fuerza mayor.

2.2. Hecho de un tercero: Corresponde a la intervención de un sujeto externo a la producción de un daño.

2.3. Culpa exclusiva de la víctima: La causa del perjuicio es una actuación u omisión de la propia víctima. Ejemplo: el suicidio que deriva directamente de la conducta del propio perjudicado.

\section{Conclusión}

Para que se configure la responsabilidad, y en consecuencia la obligación de reparar, es indispensable que la persona sea la causante del perjuicio y que no se presente ninguna de las modalidades eximentes de la responsabilidad.

\section{ELEMENTOS ESENCIALES DE LOS SEGUROS CONTRA LA RESPONSABILIDAD CIVIL}

3.1. El consentimiento: Para que exista contrato de seguros es necesario que exista acuerdo de partes.

3.2. El riesgo asegurado: u objeto, está constituido por la eventualidad de un daño en el patrimonio del asegurado, o la aparición de una deuda de responsabilidad. En el sentido estricto son los pagos de 
la eventual indemnización al tercero. El riesgo asegurado es la responsabilidad civil en que incurre el asegurado y que por efecto automático provoque una disminución potencial en su patrimonio cuya integridad garantiza el asegurado mediante el resarcimiento del daño contra el pago de una prima.

3.3. Interes asegurable: La causa o móvil, es la indemnización del daño. El asegurado contrata para quedar relevado por el asegurador de las consecuencias dañosas de su obrar antijurídico. Para ello el asegurador se obliga a mantener indemne el patrimonio del asegurado "por cuanto deba a un tercero en razón de la responsabilidad prevista en el contrato".

La obligación del asegurador en favor del asegurado nace simultáneamente con la de este en favor del tercero damnificado; con la comisión del hecho ilícito dañoso.

\subsection{El daño:}

1. el daño: como daño efectivo al patrimonio del asegurado (el asegurador evita el daño al patrimonio del asegurado pagando al tercero). ej. Se ve en los seguros obligatorios, donde el asegurado resulta obligado aunque no sea responsable del hecho dañoso, se protege al asegurado de la potencial responsabilidad incluso antes que se produzca el daño.

2. el daño como el nacimiento de la deuda de responsabilidad por la realización de la acción u omisión del responsable, que constituye el hecho generador. Lesión de un interés, la esencia es de carácter económico.

\section{EL SEGURO DE RESPONSABILIDAD CIVIL EN EL PARAGUAY}

El concepto de la Responsabilidad Civil en encuentra definido en el artículo 1644 del Código Civil Paraguayo: "Por el seguro de responsabilidad civil, el asegurador se obliga a indemnizar, por el asegurado, cuanto este llegue a deber a un tercero en razón de la responsabilidad prevista en el contrato, a consecuencia de un hecho acaecido en el plazo convenido". 
Conclusiones de la definición del seguro de responsabilidad civil:

1. Salvo pacto en contrario es un seguro de indemnidad.

2. El asegurador debe proteger el patrimonio del asegurado desde que surge el reclamo del tercero.

3. Salvo pacto en contrario, el hecho generador de la responsabilidad debe producirse durante la vigencia del contrato de seguro.

4. El reclamo del tercero puede producirse después de la vigencia del contrato de seguros.

Conforme lo expresa el Prof. Dr. Ernesto Batscheck, en el libro Código Civil de la República del Paraguay Comentado, segunda edición, Editorial La Ley paraguaya, pág. 455, y siguientes: El seguro de responsabilidad civil ha tenido en la legislación paraguaya y en la comparada, una evolución permanente. Ello así pues, de aquella suscripción de riesgos de responsabilidad civil con base en la culpa Aquiliana, se ha pasado a asumir riesgos con base en fórmulas de responsabilidad refleja o indirecta que dieron lugar a la denominada responsabilidad objetiva, es decir aquella que emerge con prescindencia de la culpa ya sea por acción u omisión, es decir, la negligencia, la imprudencia.

Esta reingeniería en el ámbito extracontractual, obviamente desencadeno, lo que más de uno dio en denominar la industria de los reclamos, pues, en alguna medida, el concepto de culpa se vio pulverizado, generando, incluso, no solo una mayor frecuencia de reclamos sino también reclamos de mayor intensidad.

En puridad se trata de hacerle responder a quien es responsable del daño causado o a quien debe hacerlo y a su vez proteger a la parte más débil de la relación que es en definitiva "LA VÍCTIMA DEL DAÑO", asumiendo un carácter más que nada tuitivo que impuso la imperiosa contingencia de crear estructuras jurídicas, económicas y técnicas capacitadas para hacer frente y asumir los riesgos comprometidos, de tal manera que las indemnizaciones requeridas para los infortunios no se tornen ilusorias.

\section{LA PROBLEMÁTICA DEL SEGURO DE RESPONSABILIDAD CIVIL EN EL PARAGUAY}

El Seguro de Responsabilidad Civil en el mercado asegurador paraguayo está caracterizado porque el mismo es voluntario, es decir no existe una legislación que obligue especialmente a los automovilistas a tomar un seguro obligatorio de responsabilidad civil. El único seguro obligatorio por ley, es el Seguro de accidentes a pasajeros, donde son considerados 
transporte público de pasajeros los (colectivos, remixes, taxis, trenes y tranvías) y tienen la obligación de circular bajo la cobertura de una póliza que cubra hasta los siguientes limites;

Las coberturas mínimas exigidas son las siguientes:

Por muerte o invalidez total o permanente de cada pasajero: Hasta la suma de US\$: 13.000 aproximadamente.

Lesiones corporales: Hasta la suma de US\$. 2.000 aproximadamente.

Esto se encuentra establecido por la ley No. 750/61 que declara obligatorio en toda la república del Paraguay el seguro contra accidentes a pasajeros de auto vehículos.

Todos los demás seguros de responsabilidad civil y en especial los de cobertura de lesiones, muerte y daños a cosas de terceros, causados por un automotor son a instancia del interés del particular, es decir que los montos de cobertura son fijados entre asegurado y asegurador.

En nuestro país, se encuentra vigente la Ley 5016/13 Nacional de tránsito y seguridad vial.

El artículo 95 de la citada Ley, establece:

SEGURO OBLIGATORIO DE ACCIDENTES DE TRÁNSITO. El seguro obligatorio de accidentes de tránsito (SOAT) que será establecido por ley (fue derogada) y exigible en todo el territorio de la república, es un seguro de tipo social que prescinde la determinación de la culpa incurrida de los involucrados en los siniestros. Su cobertura abarca los gastos correspondientes a la atención médica y quirúrgica, los gastos farmacéuticos, hospitalarios, de internación, la incapacidad permanente; así como los de transporte para la atención inmediata de los lesionados, en las cuantías establecidas por víctimas, en el correspondiente reglamento para las víctimas de accidentes de tránsito ocurridos en el territorio nacional. 


\section{ELEMENTOS EXÓGENOS QUE INCIDEN EN LA PROBLEMÁTICA DE LOS SEGUROS DE RESPONSABILIDAD CIVIL}

En Paraguay se da las siguientes características:

Que aproximadamente por cada seis (6) habitantes, se registra un automóvil.

Que la calidad del servicio del transporte público no es bueno.

Que la vía pública no está en óptimas condiciones.

Que cada vez más existan más menores conductores al volante.

Que la venta de motocicletas se realice sin ningún control.

Que no se respetan las reglas de tránsito.

Que los hospitales públicos gasten entre el 70-80 \% de su rubro, en atención a lesionados por accidentes de tránsito.

Todos estos factores inciden directa o indirectamente en las coberturas de responsabilidad civil, que circulan en nuestro mercado, y por qué decimos ello?

Afirmamos esto, porque la constante es que aquellos automóviles que cuenten con seguro de responsabilidad civil, son exigidos y obligados y por ende estos a sus aseguradoras a:

1. Dar atención inmediata a terceros lesionados, incluso en los casos que estos provocan los accidentes.

2. A indemnizar inmediatamente a los deudos de fallecidos, aun en los casos de culpa exclusiva de la víctima.

3. A que las víctimas sean atendidas en hospitales privados, cuando que los costos en estos nosocomios se triplican y las coberturas resultan insuficientes. 
El estado no puede hacer frente a las consecuencias de los accidentes de tránsito.

Cuáles son las consecuencias sociales?

Evidentemente todas estas particularidades van de la mano y determinan condiciones sociales que van formando el criterio de la función del seguro de responsabilidad civil, que si bien en principio quien lo toma (asegurado) lo hace para proteger su patrimonio de eventualidades que su acción pueda acarrear, hoy día la tendencia interpretativa de su función es la de entender que esa cobertura cumple la función de reparar el daño que sufre un tercero tanto en su integridad física como en sus bienes, y que su función es la de proteger al más débil.

\section{Evolución de los siniestros viales en Paraguay}

La siniestralidad vial en Paraguay presenta un fenómeno de variabilidad importante a partir del año 2006, relacionado con el crecimiento del número de motocicletas y ciclomotores en circulación, con el consecuente aumento de siniestros viales producidos por los mismos. Se puede decir que existe un antes y después del dicho periodo pues a partir del año 2007 se dispararon las estadísticas para arriba.

TOTAL DE FALLECIDOS POR SINIESTROS VIALES 2006-2015 MSPYBS

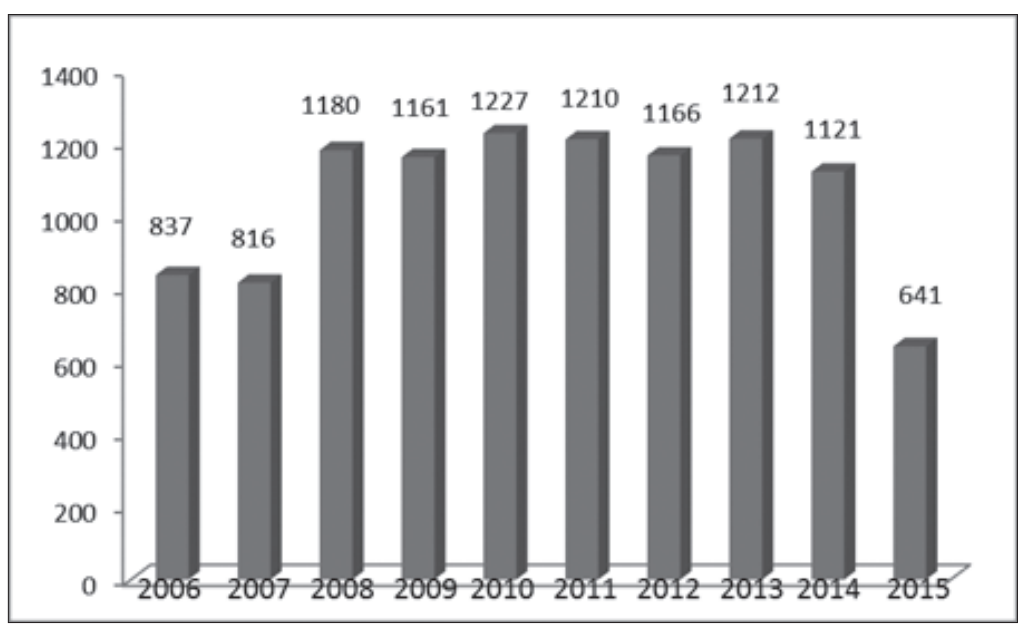




\section{DIRECCIÓN NACIONAL DEL REGISTRO DE AUTOMOTORES \\ DATOS ESTADÍSTICOS}

(Actualizado hasta Setiembre de 2015)

\begin{tabular}{|l|r|r|}
\hline \multicolumn{1}{|c|}{ Descripción Cantidad \% } & Cantidad & \% \\
\hline Automotor & 1.035 .211 & $64,06 \%$ \\
\hline Autos Antiguos & 2.482 & $0,15 \%$ \\
\hline Motocicleta & 535.385 & $33,13 \%$ \\
\hline Motos Antiguas & 238 & $0,01 \%$ \\
\hline Tractor/Maquinaria & 42.747 & $2,65 \%$ \\
\hline Total Acumulado & $\mathbf{1 . 6 1 6 . 0 6 3}$ & $\mathbf{1 0 0 \%}$ \\
\hline
\end{tabular}

\section{EL SEGURO DE RESPONSABILIDAD CIVIL EN LA LEGISLACIÓN PARAGUAYA}

En Paraguay existe una conciencia social importante que va creciendo, resultado de las estadísticas que el mercado va experimentando en la resolución de los casos en que los asegurados se ven inmersos en accidentes con lesiones y daños materiales a terceros.

Si bien como ya lo dijimos, no contamos como una legislación que obligue a tomar el seguro de responsabilidad civil, no se puede soslayar que la sociedad ha tomado conciencia de su importancia a la hora de resolver los problemas que esto acarrea, especialmente los casos de accidentes de tránsito. En el mercado paraguayo existen más de 30 compañías de seguros que suscriben pólizas de R.C.

Con respecto al seguro obligatorio, podemos comentar que la ley No: 4950/13 que creó el Seguro Obligatorio de Accidentes de Transito "SOAT", ha sido derogada por la LEY 5.150/14.

Al respecto podemos decir que se han planteado muchas interrogantes sobre la factibilidad de su aplicación, si bien en otros países tenemos conocimiento que ha dado buenos resultados.

Alguna de las objeciones a dicha ley han sido que: "A pesar del aspecto social que enfatiza esta normativa, se observan algunas fisuras que pueden colisionar en cuanto a su aplicación legal. Así el artículo 17 “el 
pago recibido como consecuencia de este seguro no implica reconocimiento ni presunción de culpabilidad que pueda perjudicar al propietario o conductor del vehículo asegurado, ni servirá como prueba, en tal sentido en caso de ejecutarse acciones civiles o penales" Pareciera que en esta ley, queda desvinculada la relación jurídica "daño-responsabilidad y culpabilidad".

"Con ello se afecta el orden público, que la justicia debe estar interesada, en función al interés general de la ley (Código Civil)". Cita del Prof. Dr. Luis Fernando Sosa Centurion.

\section{SUMAS ASEGURABLES EN RESPONSABILIDAD CIVIL EN NUESTRO SISTEMA CONTRACTUAL}

El mercado asegurador paraguayo no cuenta con una regulación legal o administrativa que nos obligue a tomar ciertos y determinados valores máximos o mínimos para el otorgamiento de esta cobertura.

Esto es así teniendo en cuenta que no existe en vigencia en la república del Paraguay, un sistema del cual se pueda concluir sin lugar a dudas, cuanto resultaría la indemnización por el fallecimiento de una persona o más, o cuanto resultaría en los casos de lesiones personales.

En nuestro país, las reclamaciones extrajudiciales derivadas de responsabilidad civil del asegurado, son negociadas en su totalidad.

Cabe resaltar que el 90\% de los casos no son judicializados y son resueltos en procedimientos conciliatorios y extrajudicialmente.

\section{CRITERIOS JURISPRUDENCIALES}

A modo ejemplificador citamos algunas resoluciones dictadas por tribunales de nuestro país.

\section{Resoluciones:}

Juicio: S.D. No 092. CAAGUAZU 28 MAYO 2012. - R.M.B. C/ W.M.O. S/ INDEMNIZACION POR DAÑOS Y PERJUICIOS. "Hacer lugar a 
la Citación en Garantía a L.C.S.A. DE SEGUROS hasta el monto de la cobertura límite establecida en la póliza de seguros contratada por el demandado, Sr. W.M.O. conforme constancia de autos."

Juicio: S.D. No 291. SAN LORENZO 20 DE JUNIO 2016 - E.D.T. L.C. S.R.L.C/ E.D.T.S.G. S/ INDEMNIZACION POR DAÑOS Y PERJUICIOS. "Hacer lugar parcialmente a la presente demanda. Condenar a los demandados E.D.T. L.C. S.R.L. a pagar a la parte actora la suma de Guaraníes XX mas un interés de 1.5 mensual a computarse a partir de la fecha de la promoción de la presente acción; con la expresa aclaración que la empresa aseguradora R.S.A. de seguros deberá responder hasta el límite máximo de la cobertura de responsabilidad civil de la póliza contratada".

Juicio: S.D. Nº 009. CAPIATA 19 DE FEBRERO 2008 - E.A.D.D. C/ M.A.M.A. S/ INDEMNIZACION POR DAÑOS Y PERJUICIOS. "Imponer, la obligación de los demandados de abonar además el interés mensual del \% calculado sobre el monto de la condena, a partir de la promoción de esta demanda, dejándose aclarado que la firma L.C.S.A. des seguros responderá en todos los casos solo hasta el límite consignado en la póliza obrante autos".

\section{Conclusión}

En síntesis podemos concluir que nuestros tribunales aplican en su sentencia montos contra las compañías de seguros hasta los límites establecidos en las pólizas.

\section{ESTADÍSTICAS DE ALGUNOS PAÍSES DE LATINOAMÉRICA CON RELACIÓN A LAS COBERTURAS DE RESPONSABILIDAD CIVIL Y EL SEGURO OBLIGATORIO DE ACCIDENTES DE TRÁNSITO}

Hemos solicitado a prestigiosos colegas de distintos países de América, nos brinden sus consideraciones sobre temas puntuales de su legislación y puntos de vista académicos que expusimos en consultas y son las siguientes: 
1) Qué tipo de seguros de Responsabilidad Civil son los más vendidos en su país? (R.C. automotores, R.C. Comprensiva, etc.)

Colombia: En Colombia es muy común la comercialización de los siguientes seguros de responsabilidad civil:

a) Responsabilidad civil por razón de la conducción de automotores como un amparo que hace parte de la póliza de automóviles.

b) Responsabilidad civil extracontractual general (también conocida como "PLO" - Predios Labores y Operaciones) y/o Responsabilidad Civil Comprensiva (según la terminología usual de reaseguro) ya sea como un seguro autónomo o asociada a seguros de cumplimiento.

c) Podría citarse una penetración del mercado cada vez mayor de los seguros Responsabilidad civil de directores y Administradores (D\&O por sus siglas en ingles) y de Responsabilidad Civil de Servidores Públicos que corresponde al producto mencionado pero adaptado a la realidad del régimen de responsabilidad de los servidores y funcionarios de las entidades del Estado.

Bolivia: Los seguros de automotores y los de todo riesgo.

Chile: La información relativa a la prima en material de Vehículos no está segregada en cuanto a los riesgos de daño propio y daño a terceros, pero el global es 6 veces mayor que la prima del riesgo de responsabilidad civil, que tampoco está segregada por especialidades, así que podemos concluir que el riesgo de RC vehicular es el más grande en el país, va abajo el cuadro de la Asociación de Aseguradores de Chile para los años 2015 y 2016. 


\begin{tabular}{|c|c|c|c|c|c|}
\hline \multirow{2}{*}{$\begin{array}{c}\text { Seguros } \\
\text { Generales }\end{array}$} & \multicolumn{2}{|c|}{ 31.12.2015 } & \multicolumn{2}{|c|}{ 31.12.2016 } & \multirow{2}{*}{$\begin{array}{l}\text { Variación } \\
2015 / 2016\end{array}$} \\
\hline & Cifra & Part. (\%) & Cifra & Part. (\%) & \\
\hline $\begin{array}{l}\text { Incendio y } \\
\text { Adicionales }\end{array}$ & 30.901 .520 & $34,0 \%$ & 30.933 .747 & $33,2 \%$ & $0,1 \%$ \\
\hline Vehículos & 24.695 .479 & $27,2 \%$ & 26.320 .328 & $28,2 \%$ & $6,6 \%$ \\
\hline Transporte & 3.242 .279 & $3,6 \%$ & 3.059 .231 & $3,3 \%$ & $-5,6 \%$ \\
\hline $\begin{array}{l}\text { Robo con } \\
\text { Fractura }\end{array}$ & 3.429 .691 & $3,8 \%$ & 3.309 .229 & $3,5 \%$ & $-3,5 \%$ \\
\hline SOAP & 1.898 .018 & $2,1 \%$ & 1.726 .786 & $1,9 \%$ & $-9,0 \%$ \\
\hline $\begin{array}{l}\text { Garantía y } \\
\text { Crédito }\end{array}$ & 3.306 .108 & $3,6 \%$ & 3.543 .739 & $3,8 \%$ & $7,2 \%$ \\
\hline $\begin{array}{l}\text { Responsabilidad } \\
\text { Civil }\end{array}$ & 4.339 .089 & $4,8 \%$ & 3.927 .606 & $4,2 \%$ & $-9,5 \%$ \\
\hline Casco & 1.380 .238 & $1,5 \%$ & 1.049 .334 & $1,1 \%$ & $-24,0 \%$ \\
\hline Ingeniería & 3.391 .148 & $3,7 \%$ & 3.147 .615 & $3,4 \%$ & $-7,2 \%$ \\
\hline Otros & 14.265 .113 & $15,7 \%$ & 16.201 .490 & $17,4 \%$ & $13,6 \%$ \\
\hline Total & 90.848 .682 & $100,0 \%$ & 93.219 .106 & $100,0 \%$ & $2,6 \%$ \\
\hline
\end{tabular}

URUGUAY: En Uruguay los seguros más vendidos son los seguros de Responsabilidad Civil de Automotores

PARAGUAY: En Paraguay los seguros más vendidos son los de RESPONSABILDAD CIVIL de Automóviles y Responsabilidad Civil Comprensiva.

\section{2) Cuáles son los seguros obligatorios en su país?}

Colombia: La obligatoriedad de los seguros debe verse desde el punto de vista bien de si lo son en cuanto a su adquisición (el cliente está en la obligación de adquirirlo) o de expedición (las aseguradoras están en la obligación de expedirlo) o mixto (tanto cliente como aseguradora deben, el primero, adquirirlo y las segundas expedirlo).

En el escenario anterior, poniendo de presente que en Colombia los seguros obligatorios solo pueden ser creados o establecidos por una norma de rango legal y no reglamentario, hemos de decir lo siguiente: 
a) El único seguro de obligatoriedad mixta (para las dos partes) es el Seguro Obligatorio de Accidentes de Tránsito - SOAT pero, aclarando que, como se dirá en el numeral siguiente, no es un seguro de responsabilidad civil.

Así las cosas, todo automóvil que transite por las carreteras del país debe contar, en todo momento, con el SOAT y el incumplimiento de dicha obligación es sancionable con multas e inmovilización del automotor. Por su parte, legalmente, las aseguradoras que tengan aprobado el ramo están en la obligación de expedirlo cuando les sea solicitado (igualmente el incumplimiento de esta obligación puede dar lugar a sanciones por parte de la Superintendencia Financiera de Colombia como órgano de vigilancia y control).

b) No existen seguros que sean de exclusiva obligatoriedad de expedición por parte de una aseguradora.

c) En tercer lugar, con relación a seguros de obligatoria adquisición por parte de los clientes (pero liberalidad de las aseguradoras de otorgarlos) tenemos, entre otros, los siguientes:

1. Seguros de responsabilidad civil para trasportadores o empresas de transporte.

- Seguro de responsabilidad civil (tanto contractual como extracontractual) de empresas de transporte de pasajeros, terrestre por carretera, por medio de taxis, escolar, por cable o especial.

- Seguro de responsabilidad civil (tanto contractual como extracontractual) para empresas de trasporte ferroviario de carga y pasajeros.

- Seguro de Responsabilidad civil (tanto contractual como extracontractual así como contaminación) para empresas de transporte fluvial.

- Seguro de responsabilidad civil extracontractual por contaminación en el caso de transporte de mercancías peligrosas.

2. Seguro de responsabilidad civil extracontractual por el transporte, almacenamiento y/o distribución de combustibles. 
3. Seguro de responsabilidad civil extracontractual de las empresas que presten servicios de vigilancia y seguridad privada.

4. Seguro de responsabilidad por contaminación ambiental para todas las actividades que requieran licencia ambiental.

5. Seguro de responsabilidad civil profesional de corredores de reaseguro.

6. Seguro de responsabilidad civil extracontractual de los propietarios de perros de razas consideradas como peligrosas por la ley.

7. Seguro de responsabilidad civil extracontractual de parques de diversiones.

Bolivia: El Seguro Obligatorio de accidentes de tránsito SOAT así como otros de aeronavegación y de responsabilidad civil medio ambiental para algunas actividades.

Chile: En rigor, sólo uno el Seguro Obligatorio de Accidentes Personales (SOAP) que ampara lesiones corporales y muerte por accidentes de vehículos.

Uruguay: Seguro de Transporte de Pasajeros y el SOA.

Paraguay: El único seguro obligatorio en Paraguay es el de Transporte Público de Pasajeros

Su país cuenta con el "SEGURO OBLIGATORIO DE ACCIDENTES DE TRANSITO”, en caso afirmativo a cuánto asciende la cobertura máxima calculada en dólares?.

Colombia: Tal como se adelantó arriba, en Colombia denominado exactamente así: "Seguro obligatorio de accidentes de tránsito", pero no es un seguro de responsabilidad civil sino que participa más de la naturaleza de una seguro de accidentes personales. Tal como se evidencia a continuación en las normas pertinentes del Estatuto Orgánico del Sistema Financiero: 


\section{ARTICULO 192. ASPECTOS GENERALES}

1. Obligatoriedad. Para transitar por el territorio nacional todo vehículo automotor debe estar amparado por un seguro obligatorio vigente que cubra los daños corporales que se causen a las personas en accidentes de tránsito. Quedan comprendidos dentro de lo previsto por este numeral los automotores extranjeros en tránsito por el territorio nacional.

Las entidades aseguradoras a que se refiere el artículo 196 numeral 1o. del presente estatuto estarán obligadas a otorgar este seguro.

2. Función social del seguro. El seguro obligatorio de daños corporales que se causen en accidentes de tránsito tiene los siguientes objetivos:

a. Cubrir la muerte o los daños corporales físicos causados a las personas; los gastos que se deban sufragar por atención médica, quirúrgica, farmacéutica, hospitalaria, incapacidad permanente; los gastos funerarios y los ocasionados por el transporte de las víctimas a las entidades del sector salud;

b. La atención de todas las víctimas de los accidentes de tránsito, incluso las de causados por vehículos automotores no asegurados o no identificados, comprendiendo al conductor del vehículo respectivo;

c. Contribuir al fortalecimiento de la infraestructura de urgencias del sistema nacional de salud, y

d. La profundización y difusión del seguro mediante la operación del sistema de seguro obligatorio de accidentes de tránsito por entidades aseguradoras que atiendan de manera responsable y oportuna sus obligaciones.

3. Definición de automotores (...)

4. Normatividad aplicable al seguro obligatorio de accidentes de tránsito. En lo no previsto en el presente capítulo el seguro obligatorio de accidentes de tránsito se regirá por las normas que regulan el contrato de seguro terrestre en el Código de Comercio y por este Estatuto". 


\section{ARTICULO 193. ASPECTOS ESPECÍFICOS RELATIVOS A LA PÓlIzA}

1. Coberturas y cuantías La póliza incluirá las siguientes coberturas:

a. Gastos médicos, quirúrgicos, farmacéuticos y hospitalarios por lesiones, de acuerdo con la cobertura que defina el Gobierno Nacional. Para la determinación de la cobertura el Gobierno Nacional deberá tener en cuenta el monto de los recursos disponibles;

Concordancias

b. Incapacidad permanente, entendiéndose por tal la prevista en los artículos 209 y 211 del Código Sustantivo del Trabajo, con una indemnización máxima de ciento ochenta (180) veces el salario mínimo legal diario vigente al momento del accidente, a la cual se le aplicarán los porcentajes contenidos en las tablas respectivas;

c. Muerte y gastos funerarios de la víctima como consecuencia del accidente, siempre y cuando ocurra dentro del año siguiente a la fecha de éste, en cuantía equivalente a setecientas cincuenta (750) veces el salario mínimo legal diario vigente al momento del accidente;

d. Gastos de transporte y movilización de las víctimas a los establecimientos hospitalarios o clínicos y las entidades de seguridad y previsión social de los subsectores oficial y privado del sector salud, en cuantía equivalente a diez (10) veces el salario mínimo legal diario vigente al momento del accidente;

PARÁGRAFO. El valor de estas coberturas se entiende fijado para cada víctima; por lo tanto, se aplicará con prescindencia del número de víctimas resultantes de un mismo accidente.

2. Vigencia de la póliza. La vigencia de la póliza de seguro de daños corporales causados a las personas en accidentes de tránsito será, cuando menos anual, excepto en seguros expedidos con carácter transitorio para los vehículos que circulen por las zonas fronterizas y para los vehículos importados que se desplacen del puerto a los concesionarios para su venta al público. Para los vehículos que ha- 
yan obtenido la clasificación como automóviles antiguos o clásicos la vigencia de dicha póliza no podrá ser menor a un trimestre.

Las autoridades de tránsito verificarán esta circunstancia.

3. Subordinación de la entrega de la póliza al pago de la prima (...)

4. Improcedencia de la duplicidad de amparos. Las coberturas del seguro obligatorio serán exclusivas del mismo y por ello no podrán incluirse en pólizas distintas a aquellas que se emitan en desarrollo de este Estatuto. Adicionalmente, las entidades aseguradoras deberán adecuar las pólizas y tarifas en las cuales exista coincidencia con las coberturas propias del seguro obligatorio, a fin de evitar duplicidad de amparos y de pago de primas.

5. Facultades del Gobierno Nacional en relación con los términos de la póliza y contribución al Fosyga. Por tratarse de un seguro obligatorio de forzosa contratación, el Gobierno Nacional, a través del Ministerio de Hacienda y Crédito Público, señalará con carácter uniforme las condiciones generales de las pólizas.

La Superintendencia Bancaria revisará periódicamente las condiciones técnicas y financieras de la operación de este seguro, propósito para el cual solicitará a las entidades aseguradoras la información que estime conveniente.

En todo caso, en la determinación de las tarifas se observarán los principios de equidad, suficiencia y moderación y se podrán establecer rangos diferenciales según la naturaleza de los riesgos".

\section{ARTICULO 194. PAGO DE INDEMNIZACIONES}

1. Prueba de los daños. En el seguro de que trata este capítulo todo pago indemnizatorio se efectuará con la demostración del accidente y de sus consecuencias dañosas para la víctima.

Se considerarán pruebas suficientes, además de todas aquellas que la víctima o el causahabiente puedan aducir, cualquiera de las siguientes que resulte pertinente, según la clase de amparo: 
a. La certificación sobre la ocurrencia del accidente. El Gobierno Nacional reglamentará la forma en que habrá de demostrarse la ocurrencia de éste. Será prueba del mismo la certificación que expida el médico que atendió inicialmente la urgencia en el centro hospitalario.

b. La certificación de la atención por lesiones corporales o de incapacidad permanente, causadas a las personas en accidentes de tránsito, expedida por cualquier entidad médica, asistencial u hospitalaria, debidamente autorizada para funcionar;

Para la expedición de esta certificación se exigirá la denuncia de la ocurrencia del accidente de tránsito, la cual podrá ser presentada por cualquier persona ante las autoridades legalmente competentes, $\mathrm{y}$

c. La certificación de pago por concepto de servicios funerarios y de exequias.

La muerte y la calidad de causahabiente se probarán con copias de las partidas de registro civil o con las pruebas supletorias del estado civil previstas en la ley.

PARÁGRAFO. El reglamento del Decreto ley 1032 de 1991 establece parámetros conforme a los cuales se racionalicen y unifiquen los mecanismos de reclamación ante las entidades aseguradoras y establece criterios y procedimientos que deberán observarse para evitar la comisión de fraudes.

2. En caso de muerte de la víctima como consecuencia de accidente de tránsito y para los efectos de este estatuto serán beneficiarios de las indemnizaciones por muerte las personas señaladas en el artículo 1142 del Código de Comercio. En todo caso a falta de cónyuge, en los casos que corresponda a éste la indemnización se tendrá como tal el compañero o compañera permanente, que acredite dicha calidad, de conformidad con la reglamentación que para el efecto señale el Gobierno Nacional. La indemnización por gastos funerarios y exequias se pagará a quien demuestre haber realizado las correspondientes erogaciones. 
Legislación anterior

3. Indemnizaciones adicionales. El pago efectuado por la entidad aseguradora que haya asumido los riesgos previstos en el presente capítulo, en relación con el automotor causante de daños corporales a las personas en accidentes de tránsito, no impedirá a la víctima o a sus derecho habientes acudir a los órganos jurisdiccionales competentes para reclamar del responsable las indemnizaciones a que crean tener derecho conforme a las normas legales.

PARAGRAFO. Las sumas pagadas por concepto de los amparos de carácter indemnizatorio de las pólizas que se emitan en desarrollo de este capítulo, se entienden prioritarias e imputables a la indemnización que por mayor valor pueda resultar a cargo del responsable del accidente.

4. Inoponibilidad de excepciones para el pago. A las víctimas de los accidentes de tránsito y sus causahabientes no les serán oponibles excepciones derivadas de vicios o defectos relativos a la celebración del contrato o al incumplimiento de obligaciones propias del tomador.

Con todo, la compañía aseguradora podrá repetir contra el tomador por cualquier suma que haya pagado como indemnización por concepto del seguro de daños causados a las personas en accidentes de tránsito, cuando éste o quien esté conduciendo el vehículo en el momento del accidente, con su autorización, haya actuado con dolo, culpa grave o dentro de aquellas circunstancias en que el seguro adolece de vicios o defectos coetáneos a su contratación.

5. Concurrencia de vehículos (...)"

Bolivia: Si se tiene el SOAT por un monto aproximado a US\$3.000.

Chile: En caso de muerte asciende por persona a US\$ 12.000 aproximadamente.

Uruguay: la cobertura máxima por muerte asciende a la suma de US\$. 30.000. En caso de varios fallecidos en un solo evento la suma máxima es prorrateada. 
En caso de lesiones se establece un baremo.

Paraguay: Como ya mencionamos, en Paraguay actualmente el único seguro obligatorio es el de Accidentes a Pasajeros, en el que cobertura máxima por muerte asciende a la suma de US\$. 12.000, por cada pasajero.

En caso de lesiones la cobertura máxima asciende a la suma de US\$. 2.000. Por pasajero

Las coberturas de responsabilidad civil de las pólizas vendidas en su país, (en cuanto a su monto), llegan a cubrir las expectativas de reclamo de los terceros damnificados?

Colombia: Esto dependerá del límite de indemnización contratado y de la extensión del daño. Ahora bien, se puede indicar lo siguiente:

En muchos casos los mínimos exigidos por la Ley para seguros obligatorios son muy bajos.

Se sublimita la cobertura de perjuicios extra patrimoniales como el daño moral o el perjuicios fisiológico a sumas bajas que en algunos casos resultan insuficientes.

Bolivia: Creo que en la mayoría de los casos si, evidentemente hay casos en los que no es suficiente.

Chile: Sí cubren el riesgo promedio, más no los casos graves.

Uruguay: En la mayoría de los casos llega a cubrir.

Paraguay: En la mayoría de los casos llega a cubrir.

Cuáles son las problemáticas más resaltantes en su país en torno a la limitación de la prestación de los seguros de responsabilidad civil?

Colombia: Entre las problemáticas más importantes se pueden considerar las siguientes: 
a) La ausencia de cobertura de los perjuicios extra patrimoniales en caso de silencio frente al amparo de los mismos, por razón de lo dispuesto en el artículo 1127 del C. de Co. En efecto, el alcance del seguro, según la norma citada, es cubrir los perjuicios patrimoniales que cause el asegurado de forma que, si nada se dice en la póliza, los extra patrimoniales no serían objeto de cobertura, especificidad técnica y legal que no es conocida ni entendida claramente por los asegurados.

Adicional a lo anterior, cuando se otorga esta cobertura generalmente es con límites muy bajos.

b) La definición de siniestro (bajo el sistema de ocurrencia) en las pólizas de seguro de responsabilidad civil extracontractual como un hecho accidental súbito e imprevisto cuando este tipo de pólizas cubren es el actuar negligente.

c) La diferencia de la prescripción de la víctima contra el causante del daño (asegurado) y la que a sui vez aplica entre el asegurado y la aseguradora. El término general aplicable a la responsabilidad civil es de 10 años mientras que la del contrato de seguro es de 2 o 5 años. Así las cosas, puede suceder (y pasa en forma frecuente) que, a partir de la reclamación (aún extrajudicial de la víctima al asegurado, empiecen a correr los términos de prescripción del seguro, los cuales podrían vencerse sin que el tercero demande, de forma que la prestación asegurativa prescriba sin que la responsabilidad del asegurado haya cesado. Por supuesto están las formas de interrumpir la prescripción pero estás no resultan siempre efectivas, claras y/o obligan a hacer erogaciones a los asegurados como en el caso de la interrupción judicial.

d) La asegurabilidad o no de las multas de acuerdo a la legislación colombiana lo cual ha sido objeto de debates importantes sin que haya uniformidad en la doctrina.

e) La restricción del límite cuantitativo de la cobertura de los gastos de defensa al límite de indemnización general de la póliza. En Colombia (por excepción al igual que Bolivia), dispone el Código de Comercio en su artículo 1128 que el asegurador pagará, "aún en exceso de la suma asegurada" este tipo de costos de forma que la cláusula que 
restringe limite asegurado para este amparo a estar dentro del límite general de indemnización de la póliza (muy común en el mercado de reaseguro) podría considerarse ilegal si se parte del supuesto que esa norma es imperativa y no se puede modificar por los contratantes, tesis acogida por la Superintendencia Financiera pero no aceptada en forma unánime por la doctrina ni por el mercado asegurador, pues algunos consideran que es una norma dispositiva y, por tanto, modificable.

f) La aplicación de la cláusula compromisoria al reclamo judicial que inicie el tercero victima contra el asegurado.

Es muy común en Colombia introducir en los seguros de responsabilidad civil cláusula de arbitraje con carácter general lo que resulta inconveniente en un caso concreto: La reclamación judicial de la víctima al asegurado pues aquella disposición contractual impide el llamamiento en garantía del asegurador dentro del mismo proceso iniciado por la víctima, obligando al asegurado iniciar un proceso arbitral sin tener aún pretensión definida pues no se le ha declarado responsable y/o no ha sido condenado a pagar una indemnización pero sí están corriendo ya los términos de prescripción. Por lo anterior, en la práctica se busca que la cláusulas de arbitraje tenga una excepción: precisamente el caso de la reclamación judicial de la víctima contra el asegurado.

Bolivia: La insuficiencia del valor asegurado para cubrir la responsabilidad y el desconocimiento en la tramitación de los reclamos.

Chile: Siendo el seguro un asunto puramente privado, el problema o su solución dependerá únicamente de la voluntad de las partes, es decir si el seguro no responde en cantidad suficiente o con la cobertura suficiente será porque no se contrató un seguro suficiente.

Uruguay: No tienen problemas con relación a la limitación de las coberturas, lo establecido en la póliza es respetada.

Paraguay: En la mayoría de los casos las coberturas otorgadas en los contratos de seguros llegan a cubrir los reclamos de terceros. Se dan ciertas particularidades donde por más que exista culpa exclusiva de la víctima, los aseguradores terminan pagando por sus asegurados a fin de evitar procesos penales para estos. 
Cuál es la opinión jurisprudencial de los tribunales de su país con relación a los límites de cobertura de responsabilidad civil establecidas en las pólizas? (esta pregunta se refiere a que si los tribunales establecen en sus sentencia que las aseguradoras son solidariamente responsables con los asegurados y hasta el monto establecido en la sentencia, independientemente a los límites de coberturas establecidos en los contratos de seguro).

Colombia: De forma general se puede decir que existe en Colombia respeto a los límites contractuales pactados en los seguros de responsabilidad civil por parte de los jueces en relación con los límites de indemnización. Pudo existir alguna que otra sentencia en contrario de tribunales de segunda instancia pero son decisiones completamente aisladas que no crearon ningún antecedente.

Bolivia: En Bolivia hay el arbitraje mandatorio, quiere decir que las controversias en seguros se resuelven en sede arbitral por lo que por la reserva de estos procesos no hay manera de conocer la tendencia jurisprudencial.

Chile: No existe en Chile una acción directa del tercero afectado contra el asegurador de quién le causó el daño, en consecuencia no se pronuncian las sentencias acerca del suficiencia del seguro.

Uruguay: Se respeta los límites establecidos en las coberturas contractuales.

Paraguay: También se respeta los límites establecidos en las coberturas contractuales, con algunas excepciones.

Con relación a las estadísticas presentadas, agradecemos la colaboración de los distinguidos colegas:

Dra. Sandra Ramírez - Bolivia

Dra. Andrea Signorino - Uruguay

Dr. Gabriel Vivas - Colombia

Dr. Ricardo Peralta - Chile 


\section{CONCLUSIONES}

La relevancia de la determinación contractual del riesgo objeto de la cobertura no requiere particular atención en nuestro caso, considerando que la obligación de indemnizar del asegurador existe dentro de los limites pactados, esta idea se destaca con la indicación que contienen las distintas modalidades de seguro, de que el asegurador se obliga dentro de los límites establecidos en la ley y el contrato, de lo cual se puede concluir que dos son los elementos que delimitan el contenido de la obligación asumida por el asegurador; de un lado, la propia descripción legal del riesgo y, de otro, la disciplina convencional que se establezca sobre el particular.

Dado que el riesgo cubierto en el seguro de responsabilidad civil es el nacimiento de la obligación de indemnizar derivada del acaecimiento de un hecho previsto en el contrato, será precisa la definición convencional del mencionado evento a fin de concretar el contenido de la obligación asumida por el asegurador.

En este sentido habrá de procederse, en primer término, a la descripción del hecho que origina la mencionada obligación indemnizatoria a cargo del asegurado, lo que se realiza generalmente mediante la referencia al ejercicio de una determinada actividad o al empleo de algún objeto.

Puede establecerse que el seguro solo cubre cierta clase de daños - por ejemplo, los materiales, lo que implicaría la exclusión de los personales - o un límite cuantitativo por siniestro, por perjudicado o de cualquier otra manera - a la prestación del asegurador. Y es posible, en fin, la delimitación personal del círculo de terceros perjudicados mediante la negación de la condición de la víctima, a los efectos del seguro de responsabilidad civil, a determinados sujetos, por lo común, familiares o empleados del propio asegurado.

La configuración en los términos descritos del riesgo en el seguro de responsabilidad civil suscita de inmediato la cuestión de la eventual calificación como cláusulas limitativas de los derechos de los asegurados de aquellas condiciones que establecen restricciones -espaciales, causales, personales- a la cobertura del asegurador respecto del hecho previsto en el contrato. 
Finalmente -reiteramos- que en nuestro país toda la problemática que se pueda presentar en torno a la limitación de la prestación de los seguros de responsabilidad civil, son resueltos a la luz de lo pactado en los contratos de seguros, en idéntico sentido, la jurisprudencia nacional se ha manifestado en sus resoluciones.

\section{BIBLIOGRAFÍA}

Signorino Barbat, Andrea, "Los seguros de responsabilidad civil" Caracteres Generales y Coberturas Principales. Fundación de Cultura Universitaria, 1er Edición, agosto de 2011 - Montevideo - Uruguay.

Stiglitz, Rubén., "Derecho de Seguros" 5ta Edición actualizada y ampliada. Tomo IV.- La Ley, Buenos Aires, 2008.

Código Civil de la República del Paraguay Comentado, Segunda Edición., La Ley Paraguaya Año 2013.

La Casa García, Rafael, "Delimitación del Riesgo y extensión personal de la cobertura en el seguro de responsabilidad civil" http:civil.udg.edu/cordoba/com

Halperin, Isaac - Barbato, Nicolás H. "SEGUROS” Lexis Nexis Depalma - Buenos Aires, 3era Edición 2011. 